\title{
Erratum to: Decision making in the Balloon Analogue Risk Task (BART): Anterior cingulate cortex signals loss aversion but not the infrequency of risky choices
}

\author{
Rena Fukunaga • Joshua W. Brown • Tim Bogg
}

Published online: 13 November 2012

(C) Psychonomic Society, Inc. 2012

Erratum to: Cogn Affect Behav Neurosci

DOI 10.3758/s13415-012-0102-1

The publisher inadvertently neglected to make the supplementary material document available online. The supplementary material is now available for download.

Electronic supplementary material The online version of this article (doi:10.3758/s13415-012-0127-5) contains supplementary material, which is available to authorized users.

The online version of the original article can be found at http://dx.doi.org/ 10.3758/s13415-012-0102-1.

R. Fukunaga $\cdot$ J. W. Brown $(\bowtie)$

Department of Psychological and Brain Sciences,

1101 E Tenth Street,

Bloomington, IN 47405, USA

e-mail: jwmbrown@indiana.edu

T. Bogg

Department of Psychology, Wayne State University,

5057 Woodward Avenue, 7th Floor,

Detroit, MI 48202, USA 